\title{
The Effect of Hemicellulose Content on Mechanical Strength, Thermal Stability, and Water Resistance of Cellulose-rich Fiber Material from Poplar
}

\author{
Quanliang Wang, ${ }^{a}$ Shengling Xiao, ${ }^{\mathrm{a}, *}$ and Sheldon Q. Shi ${ }^{\mathrm{b}}$ \\ The hemicellulose content of cellulosic material from poplar chemi- \\ thermomechanical pulp (CTMP) was controlled by a microwave-assisted \\ formic acid (MFA) extraction process. The environmentally friendly, self- \\ bonded, and cellulose-rich fiber sheets (around $0.3 \mathrm{~mm}$ thick and 280 \\ $\mathrm{g} / \mathrm{m}^{2}$ grammage) were fabricated via a molding and compression \\ process. The results showed that the MFA treatment effectively \\ controlled the hemicellulose content in the range from $6.8 \%$ to $20.4 \%$. \\ Mechanical testing results showed a good linear relationship between \\ the tensile strength and the hemicellulose content, where a higher \\ hemicellulose content obtained a stronger tensile strength. Meanwhile, \\ as hemicellulose content decreased, the onset temperature, representing \\ the thermal stability, increased from $318.1^{\circ} \mathrm{C}$ to $335.7^{\circ} \mathrm{C}$ and the elastic \\ modulus, representing the mechanical stiffness, increased from 0.047 \\ $\mathrm{MPa}$ to $0.068 \mathrm{MPa}$. Additionally, as the hemicellulose content decreased, \\ the water-resistance of the cellulose-rich fiber sheets improved. During \\ the hemicellulose removal process, the strength of single fibers was \\ found to have a dominant role in the mechanical strength of the \\ cellulose-rich fiber sheets, rather than the inter-fiber bonding strength. \\ This was contrary to research on the delignification process, where the \\ inter-fiber bonding strength was found to be more important than the \\ strength of single fibers in deciding the material strength.
}

Keywords: Hemicellulose content; Formic acid extraction; Microwave; Tensile strength; Thermal stability; Cellulose-rich fiber; Self-bonded mechanism

Contact information: a: College of Engineering and Technology, Northeast Forestry University, Harbin 150040, China; b: Department of Mechanical and Energy Engineering, University of North Texas, Denton, TX 76203, USA; *Corresponding author: shenglingxiao@126.com

\section{INTRODUCTION}

Self-bonded cellulosic fiber materials can be fabricated via the molding and compression process using pulp fibers (Nilsson et al. 2012). Cellulosic fiber materials possess excellent mechanical strength, hydrophobic characteristics, magnetic response properties, and electromagnetic interference shielding through the controllable molding and functional modification process (Xia et al. 2016a; Gan et al. 2017). Cellulosic fibers can form thick-walled flat fiberboard, as well as arbitrary three-dimensional structures. These characteristics make cellulosic fiber materials promising for applications in the fields of medical care, construction, machinery, electronics, and transportation (Gan et al. 2015; Segmehl et al. 2018). Bleached cellulose-rich fiber materials possess a bright and clean visual appearance, allowing for promising applications, such as medical devices (Wang et al. 2017a). 
Typical cellulosic fiber materials as used in papermaking are mostly comprised of delignified fiber and are typically applied in the logistics and packaging fields with thinwalled and/or low-density three-dimensional structures possessing low mechanical strength (Ou and Huang 2003; Wang and Li 2014). In this study, a new type of cellulosic fiber material was developed. This new cellulosic fiber material has better mechanical strength. Its use has been widely explored in various feedstocks, fabricating techniques, and applications (Xia et al. 2016b; Wang et al. 2017b). Replacing formaldehydecontaining gluing materials or even petroleum derivatives with environmentally friendly fiber materials is of far-reaching significance with the ever-increasing demand for environmental protection (Wu et al. 2018).

Cellulosic fibers are mainly composed of cellulose, hemicellulose, and lignin. While cellulose is retained as the main component of fibers to form the final product, hemicellulose and lignin are partially or completely removed to improve the performance of the product (Karimi et al. 2006; Chen et al. 2010; Wan et al. 2010). In addition, it was reported that adding the xylan extracts or hemicellulosic derivatives into the pulp fibers could improve the physical properties of paper handsheets (Ren et al. 2009; Ban et al. 2011).

Spiegelberg (1966) also used a three-step aqueous alkaline extractions to selectively remove the hemicelluloses from the holocellulose pulp fibers, and found that partial removal of the hemicelluloses lowered the breaking stress, modulus of elasticity, and yield point stress of individual fibers. It can be found that the hemicelluloses (adding or removal) have an important role in deciding the pulp physical strength.

However, during the hemicellulose removal process, the fiber cell wall structures may undergo complex changes, which thus affects the formed cellulosic fiber materials, especially for the high-density fiber products relying more on the inter-fiber bonding and single fiber strength (Wang et al. 2018). Therefore, it is necessary to study the effect of hemicellulose components on the properties of high-performance natural fiber materials. Hemicelluloses are the amorphous components of carbohydrates for natural fibers, which are a mixture of oligosaccharides containing various glycosyls (Riansa-Ngawong et al. 2011; Zhang et al. 2016).

The effective separation of hemicellulose from cellulose is always a challenge due to their close spatial bindings and similar structures (Jiang et al. 2018). The existing methods for hemicellulose removal mainly include hot water extraction, acid hydrolysis, caustic extraction, enzymatic hydrolysis, and organosolv extraction (Goldmann et al. 2017; Li et al. 2017a).

In this work, a microwave-assisted formic acid (MFA) extraction process was used for the separation of hemicellulose. The treatment was performed under mild conditions $\left(100{ }^{\circ} \mathrm{C}\right)$ for controlled removal of the hemicellulose from poplar chemithermomechanical pulp (CTMP).

The characterizations of cellulose-rich fiber materials were performed via measuring chemical compositions, X-ray diffraction (XRD), and scanning electron microscopy (SEM). The mechanical, water-resistant, and thermal properties of the cellulose-rich fiber sheets were investigated using thermogravimetric analysis (TGA), mechanical testing, and the water contact angle (WCA). 


\section{EXPERIMENTAL}

\section{Materials}

Preparation of the cellulose-rich fibers with various hemicellulose content by the MFA process

Chemi-thermomechanical pulp (CTMP) of poplar residue (Baihe Forestry Bureau, Jilin, China) was prepared in the laboratory and used as the starting material. All the reagents used were purchased from Sinopharm Chemical Reagent Co. (Beijing, China).

The MFA extraction process was employed for the hemicellulose separation. A total of $4 \mathrm{~g}$ of dry poplar CTMP (101-3A Oven; Teste Co., Tianjin, China ), and $120 \mathrm{~mL}$ of formic acid aqueous solution ( $88 \mathrm{wt} \%$ ) were placed in a $500 \mathrm{~mL}$ Erlenmeyer flask, shaken well, buckled with a conical flask, and heated using a microwave oven (EG720KG3-NR1; Midea, Beijing, China). The solution was split into three samples, which were heated at $100{ }^{\circ} \mathrm{C}$ for $0.5 \mathrm{~h}, 1.5 \mathrm{~h}$, and $4.0 \mathrm{~h}$. The cellulose-rich solids (CRS) were then separated from the liquid hydrolysate via vacuum filtration (SHZ-D Vacuum Pump; Yite Instrument Co., Zhengzhou, China) through a filtering crucible (Yuhang Xingye Co., Harbin, China). Then, the additional $120 \mathrm{~mL}$ of formic acid solution ( 88 wt $\%$ ) and the separated CRS were added into the flask again and each sample was heated in the microwave oven at $100{ }^{\circ} \mathrm{C}$ for $0.5 \mathrm{~h}, 1.5 \mathrm{~h}$, and $4 \mathrm{~h}$. Finally, the CRS and the liquid hydrolysate were further separated.

The collected CRS were bleached to remove the residual lignin. The CRS derived from the $4 \mathrm{~g}$ of original pulp fibers were added into a $250 \mathrm{~mL}$ quartz flask, which was filled with $130 \mathrm{~mL}$ of distilled water, $1.0 \mathrm{~mL}$ of acetic acid $(99.7 \mathrm{wt} \%)$, and $1.5 \mathrm{~g}$ of sodium chlorite $(80 \mathrm{wt} \%)$. The liquid mixture was then heated at $75^{\circ} \mathrm{C}$ for $1 \mathrm{~h}$. The same delignification procedure was operated two more time, and thus it was thought that the residual lignin was completely removed according to our previous research (Wang et al. 2017a).

In the end, the MFA-treated, cellulose-rich fibers (i.e., the bleached CRS) were obtained after being separated from the mixture and fully washed until a neutral $\mathrm{pH}$ was reached. The fiber samples were designated by the total time they were treated by formic acid in the lower case, i.e., fiber ${ }_{1.0}$, fiber 3.0 , and fiber8.0. Fiber 0.0 was the control sample, which was prepared without formic acid. The fiber 0.0 sample was bleached using the same procedure as the other CRS samples, but it was directly bleached three additional times after the first bleaching treatment.

\section{Preparation of the cellulose-rich fiber sheets}

The bleached CRS with different hemicellulose contents were molded using a ZT7-01 shaper (Xingping Zhongtong Test Equipment Co., Xingping, China). Then, the processes of pre-compaction and hot-pressing were conducted on a ZG-20T thermocompressor (Dongguan Zhengyong Electronic Mechanical Co., Dongguan, China). The pre-compaction treatment was completed under $2 \mathrm{MPa}$ and at room temperature (RT) for $1 \mathrm{~min}$. The hot-pressing process was performed under $4 \mathrm{MPa}$ and at $170{ }^{\circ} \mathrm{C}$ for $15 \mathrm{~min}$. The cellulose-rich hot-pressed samples (about $280 \mathrm{~g} / \mathrm{m}^{2}$ grammage) were designated as Pr-fiber with the same lower-case nomenclature as indicated above. 


\section{Methods}

Characterizations of the cellulose-rich fiber sheets

The hemicellulose content of the cellulose-rich fiber sheets was determined according to the standard GB/T 745-2003 (2003). The bleached CRS were mainly composed of cellulose, with a small amount of hemicellulose. The cellulose content in the cellulose-rich fibers was evaluated according to Eq.1,

$$
\text { Cellulose content }(\%)=\left(1-\frac{H}{C}\right) \times 100
$$

where $H$ is the weight of hemicelluloses in the bleached CRS sample (g) and $C$ is the weight of the bleached CRS sample $(\mathrm{g})$.

The XRD patterns were recorded on an X-ray diffractometer (D/max 2200; Rigaku, Tokyo, Japan) in the range of $2 \theta=5^{\circ}$ to $45^{\circ}$ with a scan rate of $6^{\circ} / \mathrm{min}$. The crystallinity index (CrI) was calculated according to Eq. 2 (Segal et al. 1959),

$$
\operatorname{CrI}(\%)=\left(1-\frac{I_{a m}}{I_{200}}\right) \times 100
$$

where $I_{200}$ is the intensity (A.U.) of the 200 peak at $2 \theta=22.8^{\circ}$ and the $I_{\mathrm{am}}$ is the minimum intensity (A.U.) at the amorphous region of $2 \theta=18^{\circ}$.

The surface and cross-section morphologies of the cellulose-rich fiber sheets were gold-coated and observed using a Quanta-200 scanning electron microscope (FEI Company, Denver, USA). The cross-sections were prepared by a microtome blade (R-35; Feather, Osaka, Japan).

Mechanical, water-resistant, and thermal properties of the cellulose-rich fiber sheets

The tensile strength tests were performed on a CMT5504 universal mechanical testing machine (Shenzhen SANS Testing Machine Co., Shenzhen, China) according to the standard GB/T 1040.3-2006 (2006). Block samples $150 \mathrm{~mm} \times 15 \mathrm{~mm}$ in size were prepared and placed at RT for $24 \mathrm{~h}$ before the mechanical test.

The TGA thermogram was recorded on an SDT Q600 simultaneous thermal analyzer (TA Instruments, New Castle, USA) within a temperature range of RT to 500 ${ }^{\circ} \mathrm{C}$. A heating rate of $10{ }^{\circ} \mathrm{C} / \mathrm{min}$ was applied under the nitrogen flow of $100 \mathrm{~mL} / \mathrm{min}$. The samples (approximately $2.0 \mathrm{mg}$ ) were placed at RT for $24 \mathrm{~h}$ before the test.

The water contact angle (WCA) was measured on an OCA20 contact angle analyzer (Data Physics Co., Filderstadt, Germany). The average value of five measurements at different places was reported as the result.

\section{RESULTS AND DISCUSSION}

\section{The MFA Process for the Cellulose-rich Fiber Sheets}

A clean and high-strength cellulose-rich fiber sheet with adjustable properties was developed for various promising applications, such as medical appliances. The fabrication process of the fiber sheet is illustrated in Fig. 1. The mechanical strength, thermal stability, and water-resistance can be adjusted by changing the hemicellulose content, which is further controlled by the MFA treatment. A mild and recyclable MFA extraction process was used to prepare the cellulose-rich fibers from poplar residue. 


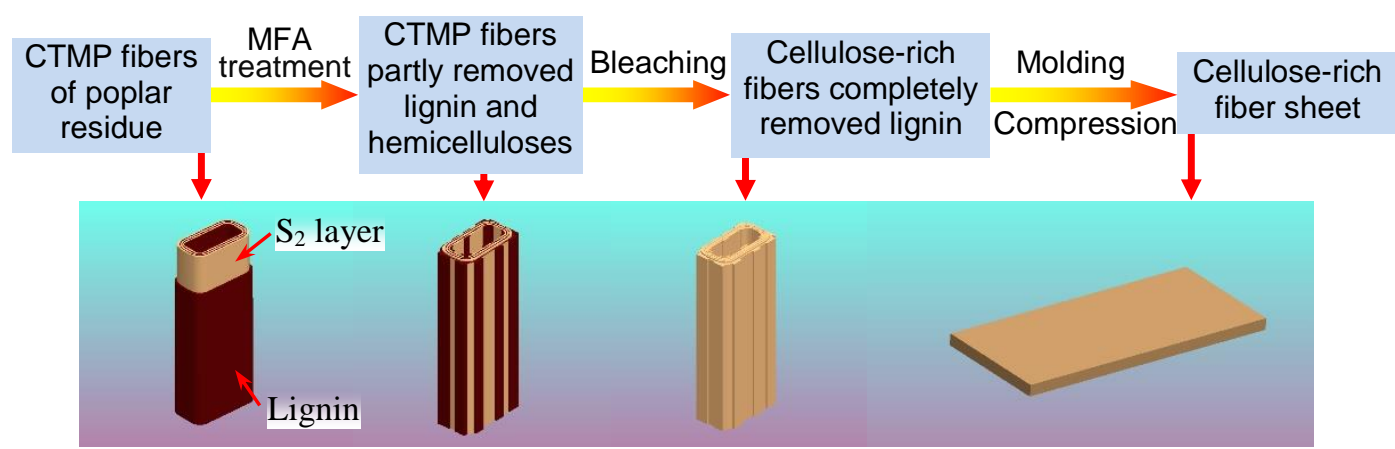

Fig. 1. Illustration of the MFA treatment and compression molding processes for the stepwise removal of hemicelluloses and lignin, and the fabrication of cellulose-rich fiber sheet

The MFA approach achieved the simultaneous removal of the hemicellulose and most of the lignin. This approach effectively separated the hemicellulose from the cellulose and reduced the bleaching chemical consumption.

The microwave irradiation was able to quickly and uniformly heat up the fibers $(\leq$ $100{ }^{\circ} \mathrm{C}$ ) and promote the penetration of the formic acid into the fibers. The formic acid solvent was easily recycled for reutilization because no additional inorganic acids were added. The hemicellulose can be selectively removed without damaging the cellulose due to the presence of formyl groups during cellulose formylation, preventing the further hydrolysis of cellulose (Zhao and Liu 2012).

\section{Characterizations in the Composition, Crystallinity, and Morphology of the Fiber Sheets}

The hemicellulose content in the cellulose-rich fibers was controlled by the MFA treatment process with different treatment times. The hemicellulose and cellulose contents of the cellulose-rich fibers are shown in Fig. 2. The hemicellulose content was reduced as the treatment time increased.

As the hemicellulose content decreased from $20.4 \%$ to $6.8 \%$, the cellulose content increased from $79.6 \%$ to $93.2 \%$. The effective removal of the hemicellulose was attributed to the introduction of the microwave irradiation, which facilitated the penetration of the formic acid into the fibers, achieving the selective removal of hemicellulose (Zhao and Liu 2012; Liu et al. 2018).

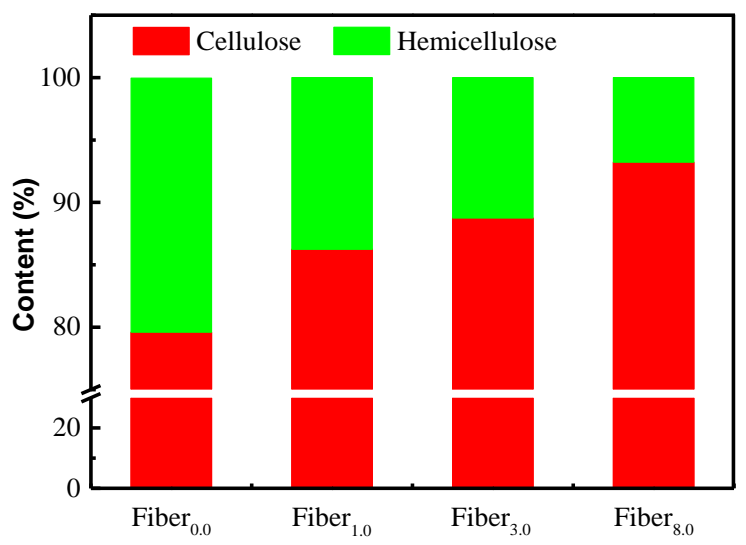

Fig. 2. Hemicellulose and cellulose contents of the cellulose-rich fibers

Wang et al. (2019). "Hemicellulose \& fiber properties," BioResources 14(3), 5288-5300. 5292 
The XRD patterns and crystallinity indices of the cellulose-rich fibers and fiber sheets are displayed in Fig. 3. Both the fibers and the fiber sheets showed the typical XRD pattern of cellulose I with diffraction peaks near $2 \theta=14.2^{\circ}(101), 16.2^{\circ}(101)$, and $22.8^{\circ}$ (200) (Nam et al. 2016; Jin et al. 2017), indicating that the hemicellulose removal or hot- pressing treatment did not change the crystal structure. As the MFA treatment time was increased from $0 \mathrm{~h}$ to $8 \mathrm{~h}$, the crystallinity of the fibers considerably increased from $63.4 \%$ to $77.5 \%$. This was attributed to the removal of amorphous hemicellulose from the cellulose. The crystallinity indexes of fiber $_{0.0}$, fiber fi. $_{1.0}$ and fiber $_{3.0}$ were significantly increased after hot-pressing, which was attributed to the partial cocrystallization of crystallites in the adjacent fibrils. This was in agreement with previous research (Wang et al. 2018). The hot-pressing treatment helps to improve the crystallinity of the fibers, which is beneficial to the dimensional stability of fiber sheets (Ariawan et al. 2015). Interestingly, it was found that the crystallinity value of the fiber 8.0 sample decreased from $77.5 \%$ to $75.1 \%$ after hot-pressing, which indicated that hot-pressing had an adverse effect on high-crystallinity fibers to form the fiber sheet. This could be owing to disturbance of the regular aggregation of elemental fibrils in high crystallinity fibers under high pressure treatment, which thus led to the decrease of crystallinity (Chen et al. 2018).

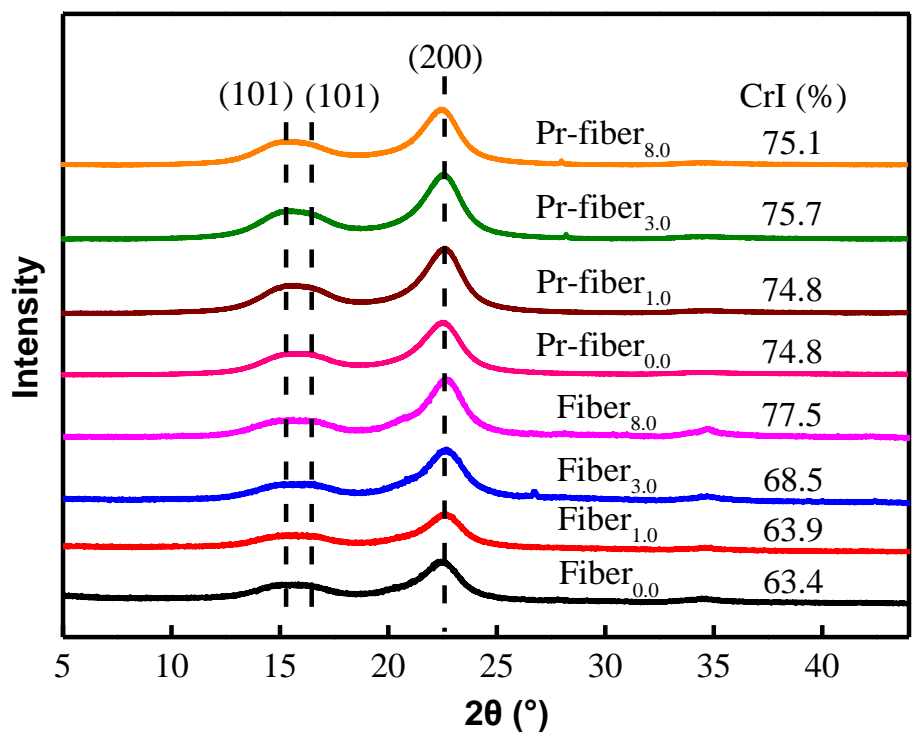

Fig. 3. XRD patterns of the cellulose-rich fibers and fiber sheets

The morphology of the cellulose-rich fiber sheets is shown in Fig. 4. With the removal of the hemicellulose, the structures of the fiber cell wall were gradually chemically-etched accompanied by an increased roughness, and some fibers appeared to be separated into dissociated fiber blocks (Figs. 4a through 4c). Therefore, with the destruction of fiber cell walls, a decrease in the mechanical strength of single fibers could be anticipated. However, the removal of hemicellulose promoted inter-fiber contact (Figs. 4d through 4f), which demonstrated that the fiber sheets with less hemicellulose experienced enhanced inter-fiber bonding strength. The cross-sectional images of the fiber sheets (Figs. $4 \mathrm{~g}$ through $4 \mathrm{i}$ ) show that the samples with prolonged treatment had less cracks and a higher density, increasing from $0.91 \mathrm{~g} / \mathrm{cm}^{3}$ to $0.97 \mathrm{~g} / \mathrm{cm}^{3}$. With prolonged 
treatment, the hemicellulose content decreased from $20.4 \%$ to $6.8 \%$, which further confirmed the enhancement of the inter-fiber bonding.
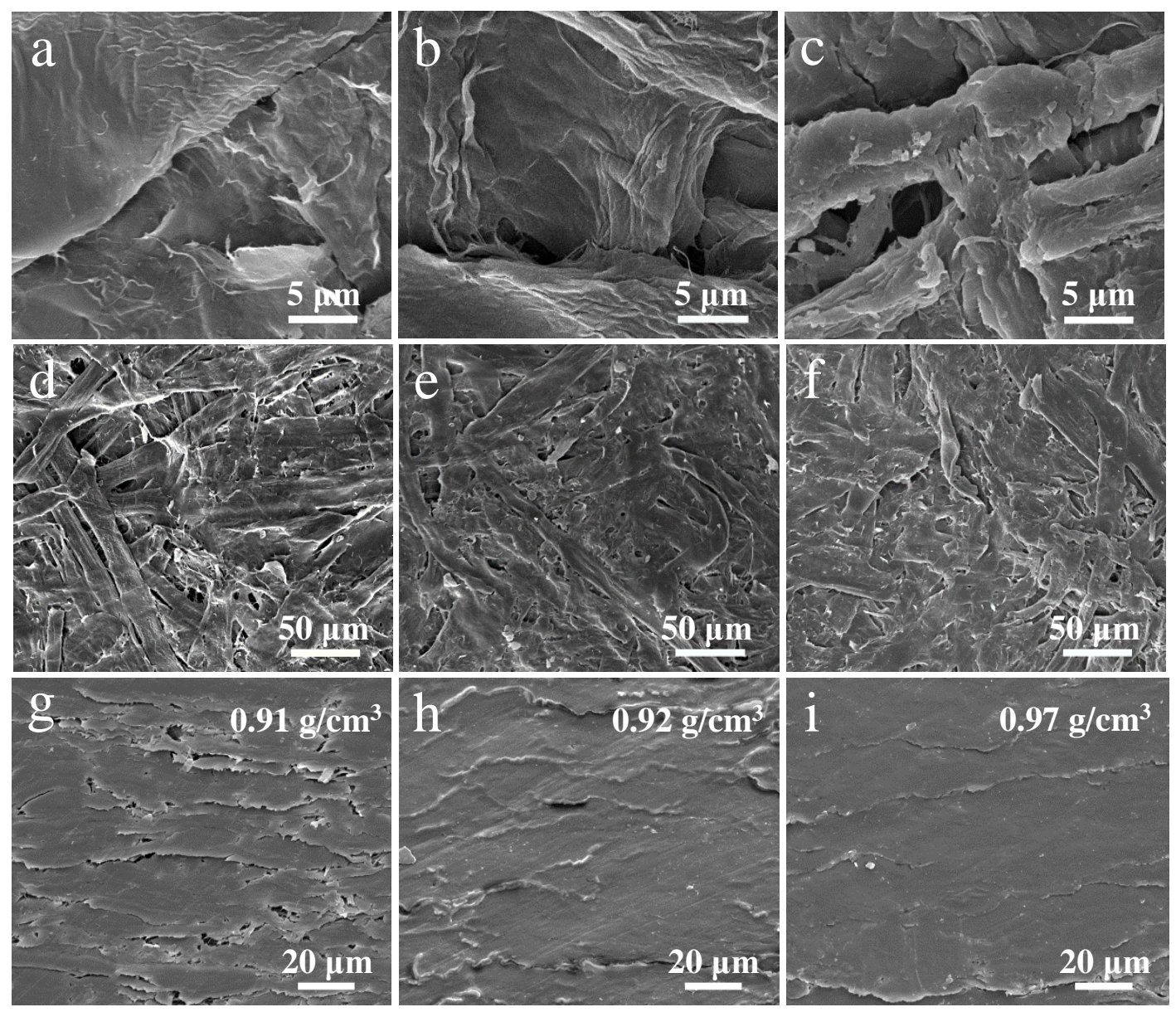

Fig. 4. SEM images for (a, d, and g) Pr-fiber 0.0 , (b, e, and h) Pr-fiber ${ }_{1.0}$, and (c, f, and i) Pr-fiber 8.0 ; (a through $f$ ) outer surface and ( $g$ through i) cross section

\section{Mechanical, Thermal, and Water-resistant Performance of the Cellulose- rich Fiber Sheets}

The mechanical performance of the fiber sheets $(0.3 \mathrm{~mm}$ thick $)$ was evaluated by tensile testing. The tensile strength and elastic modulus of the sheets are shown in Fig. 5.

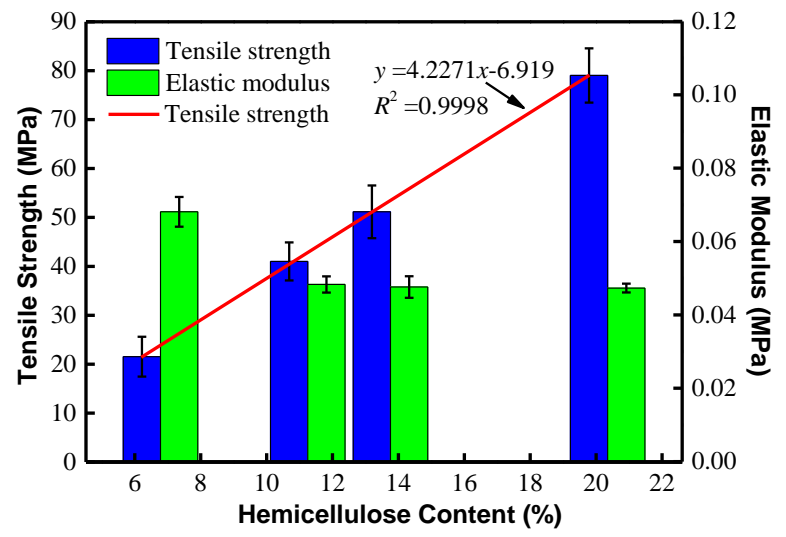

Fig. 5. Mechanical strength of the cellulose-rich fiber sheets 
There was a linear relationship between the tensile strength and the hemicellulose content, as samples with a higher hemicellulose content exhibited higher tensile strength. However, the elastic modulus of the fiber sheets increased from $0.047 \mathrm{MPa}$ to $0.068 \mathrm{MPa}$ as the hemicellulose content decreased from $20.4 \%$ to $6.8 \%$, which could be attributed to the increased crystallinity degree (seen in Fig. 3) of the fiber sheets.

The mechanical strength test results combined with the SEM observations (Fig. 4) provide evidence for the fact that the strength of individual fibers played a dominant role in the tensile strength of cellulose-rich fiber sheets, rather than the inter-fiber bonding strength or the material crystallinity during the hemicellulose removal process. This finding is contrary to previous work regarding the effect of delignification on material strength, which found that inter-fiber bonding is more important than the strength of individual fibers in determining the material strength. This finding is of great importance to the comprehensive understanding of the self-bonded mechanism for natural fiber materials.

The thermal properties of the cellulose-rich fiber sheets were investigated using TGA and DTG, as shown in Fig. 6. The TGA survey curves showed three stages of weight loss on the thermal decomposition, where the temperature ranges of $25^{\circ} \mathrm{C}$ to 180 ${ }^{\circ} \mathrm{C}, 180{ }^{\circ} \mathrm{C}$ to $385{ }^{\circ} \mathrm{C}$, and $385{ }^{\circ} \mathrm{C}$ to $500{ }^{\circ} \mathrm{C}$ correspond to the dehydration of free/bound water, the thermal depolymerization of carbohydrates, and the further degradation/carbonization of intermediates, respectively (Li et al. 2017b; Naduparambath et al. 2017).

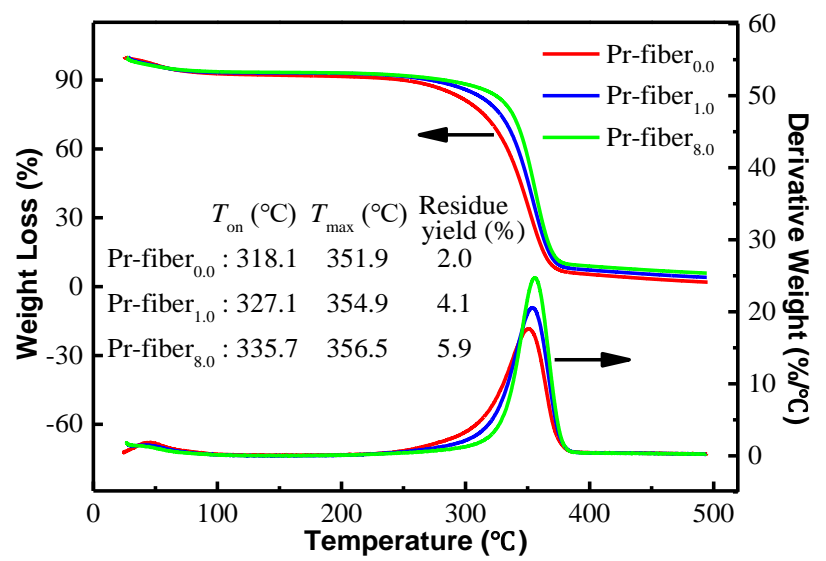

Fig. 6. The TGA and derivative thermogravimetry (DTG) survey curves of the cellulose-rich fiber sheets

The thermal stability of the cellulose-rich fiber sheets can be observed in the second stage of the TGA curves (Fig. 6), which showed that the major decomposition of hemicellulose and cellulose occurred between $180{ }^{\circ} \mathrm{C}$ and $385{ }^{\circ} \mathrm{C}$ (Haykiri-Acma et al. 2010; Shen et al. 2010). The thermal stability of the fiber sheets improved with the removal of hemicellulose, as the onset temperature increased from $318.1{ }^{\circ} \mathrm{C}$ for $\operatorname{Pr}_{\text {-fiber }} 0.0$ to $335.7{ }^{\circ} \mathrm{C}$ for $\operatorname{Pr}$-fiber 8.0 . The maximum degradation rate temperature $\left(T_{\max }\right)$, which corresponded to the thermal decomposition of cellulose, exhibited a slight increase from $351.9{ }^{\circ} \mathrm{C}$ to $356.5{ }^{\circ} \mathrm{C}$ as the hemicellulose content decreased from $20.4 \%$ to $6.8 \%$. The residue yield was increased from $2.0 \%$ for the Pr-fiber 0.0 to $5.9 \%$ for the Pr-fiber 8.0 at $495^{\circ} \mathrm{C}$. Therefore, these results demonstrated good thermal stability and strong retention of cellulose during the hemicellulose removal process. 

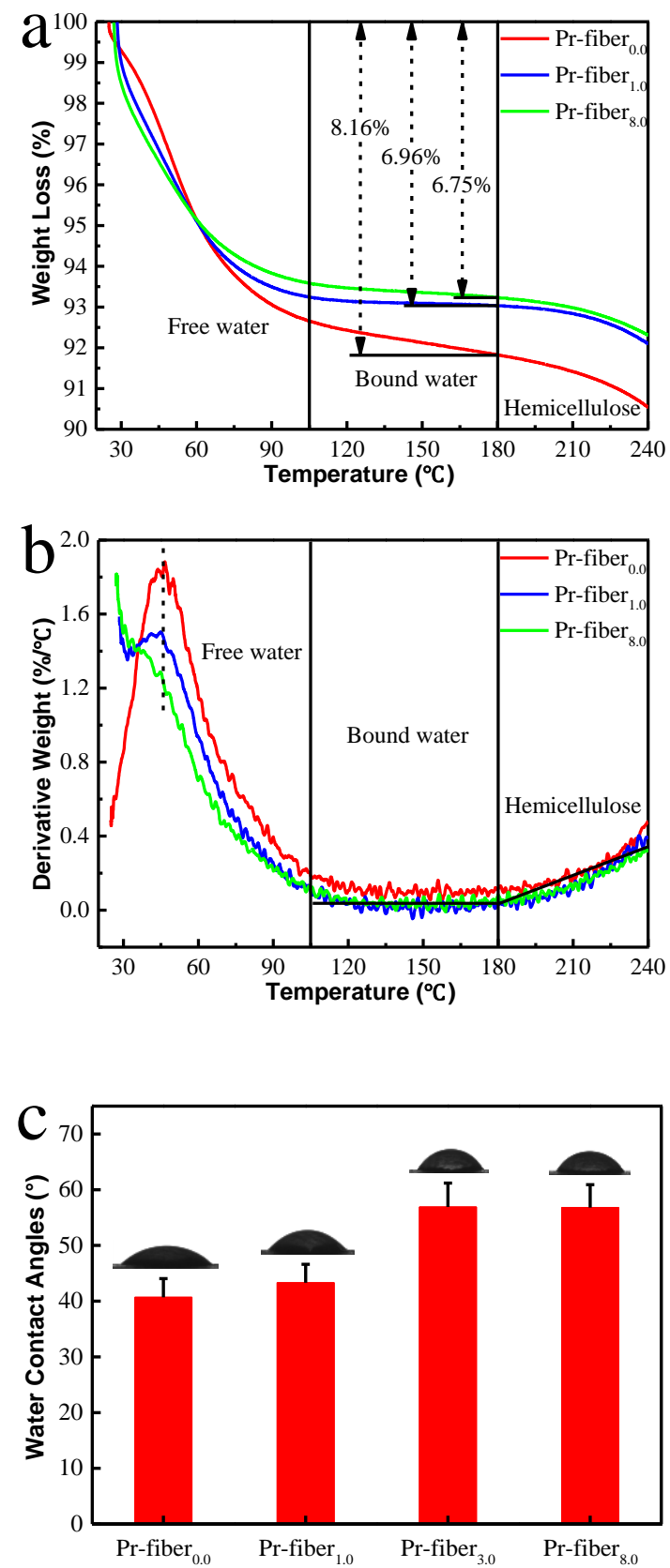

Fig. 7. The (a) high-magnification TGA curves, (b) high-magnification DTG curves, and (c) WCAs of the cellulose-rich fiber sheets

The water-resistant performance of the cellulose-rich fiber sheets was evaluated from two aspects: hygroscopicity and hydrophobicity. The hygroscopicity of the cellulose -rich fiber sheets can be seen in the TGA/DTG curves (Figs. 7a and b). The initial weight loss for all Pr-fibers mainly stemmed from the evaporation of free water $\left(25^{\circ} \mathrm{C}\right.$ to 105 ${ }^{\circ} \mathrm{C}$ ) and bound water $\left(105{ }^{\circ} \mathrm{C}\right.$ to $\left.180{ }^{\circ} \mathrm{C}\right)$ (Park et al. 2007; Tian et al. 2011; Xie et al. 2016). A maximum weight loss rate of free water was observed at approximately $45^{\circ} \mathrm{C}$ and a constant rate of weight loss for bound water was observed between $105{ }^{\circ} \mathrm{C}$ and 180 ${ }^{\circ} \mathrm{C}$. As the hemicellulose content decreased, all of the fiber sheets showed reduced 
hygroscopicity, where the moisture absorption decreased from $8.16 \%$ to $6.75 \%$ as the hemicellulose content decreased from $20.4 \%$ to $6.8 \%$.

The surface hydrophobicity was analyzed through measuring the WCA at the contact time of $30 \mathrm{~s}$ (Fig. 7c). The WCA increased from $40.7^{\circ}$ for Pr-fiber 0.0 to $56.8^{\circ}$ for Pr-fiber 8.0 , indicating that the hydrophobicity improved as the hemicellulose content decreased. According to SEM observations (Fig. 4), the fiber sheet exhibited a smoother surface with the removal of hemicellulose. Usually, the enhancement of surface hydrophobicity is achieved by increasing the surface roughness or by lowering the surface free energy (Wang et al. 2017a). Thus, the enhanced surface hydrophobicity could be attributed to the improved surface free energy with the decreased hemicellulose content.

\section{CONCLUSIONS}

1. The hemicellulose content of poplar chemi-thermomechanical pulp (CTMP) was effectively controlled in the range from $6.8 \%$ to $20.4 \%$ by the mild and recyclable microwave-assisted formic acid (MFA) process.

2. A clean and high-strength cellulose-rich fiber sheet $(0.3 \mathrm{~mm}$ thick) was prepared by the facile molding and compression process. By controlling the hemicellulose content, various mechanical, water-resistant, and thermal performance properties were obtained.

3. A good linear function between the tensile strength and the hemicellulose content was observed, where a higher hemicellulose content produced sheets with higher tensile strength. Meanwhile, decreasing the hemicellulose content from $20.4 \%$ to $6.8 \%$ was shown to increase the thermal stability by raising the onset temperature from 318.1 to $335.7{ }^{\circ} \mathrm{C}$, enhance the mechanical stiffness by raising the elastic modulus from 0.047 $\mathrm{MPa}$ to $0.068 \mathrm{MPa}$, and improve the water-resistant performance by changing the hygroscopicity and hydrophobicity of the cellulose-rich fiber materials.

4. A new understanding to the self-bonded mechanism of cellulose-rich fiber materials for the hemicellulose removal process was established. It was found that the strength of single fibers plays a dominant role in the material strength instead of the inter-fiber bonding strength under the conditions employed in the present study. These results are different from those of studies focused on the effects of delignification.

\section{ACKNOWLEDGEMENTS}

This work was financially supported by the National Key R\&D Program of China (Grant No. 2017YFD0601004) and the Applied Technology Research and Development Project of Harbin (Grant No. 2016RAXXJ004). 


\section{REFERENCES CITED}

Ariawan, D., Ishak, Z. A. M., Salim, M. S., Taib, R. M., and Thirmizir, M. Z. A. (2015). "Wettability and interfacial characterization of alkaline treated kenaf fiberunsaturated polyester composites fabricated by resin transfer molding," Polym. Composite. 38(3), 507-515. DOI: 10.1002/pc.23609

Ban, W., Chen, X., Andrews, G., and Van Heiningen, A. (2011). "Influence of hemicelluloses pre-extraction and re-adsorption on pulp physical strength. II. Beatability and strength study," Cell. Chem. Technol. 45(9-10), 633-641.

Chen, W., Yu, H., Lee, S.-Y., Wei, T., Li, J., Fan, Z. (2018). "Nanocellulose: A promising nanomaterial for advanced electrochemical energy storage," Chem. Soc. Rev. 47(8), 2837-2872. DOI: 10.1039/C7CS00790F

Chen, Y., Wang, Y., Wan, J., and Ma, Y. (2010). "Crystal and pore structure of wheat straw cellulose fiber during recycling," Cellulose 17(2), 329-338. DOI: 10.1007/s10570-009-9368-Z

Gan, W., Gao, L., Sun, Q., Jin, C., Lu, Y., and Li, J. (2015). "Multifunctional wood materials with magnetic, superhydrophobic and anti-ultraviolet properties," Appl. Surf. Sci. 332, 565-572. DOI: 10.1016/j.apsusc.2015.01.206

Gan, W., Gao, L., Xiao, S., Zhang, W., Zhan, X., and Li, J. (2017). “Transparent magnetic wood composites based on immobilizing $\mathrm{Fe}_{3} \mathrm{O}_{4}$ nanoparticles into a delignified wood template," J. Mater. Sci. 52(6), 3321-3329. DOI: 10.1007/s10853-016-0619-8

GB/T 745-2003 (2003). "Pulps - Determination of pentosan content," Standardization Administration of China, Beijing, China.

GB/T 1040.3-2006 (2006). "Plastics - Determination of tensile properties - Part 3: Test conditions for films and sheets," Standardization Administration of China, Beijing, China.

Goldmann, W. M., Ahola, J., Mikola, M., and Tanskanen, J. (2017). "Formic acid aided hot water extraction of hemicellulose from European silver birch (Betula pendula) sawdust," Bioresource Technol. 232, 176-182. DOI: 10.1016/j.biortech.2017.02.032

Haykiri-Acma, H., Yaman, S., and Kucukbayrak, S. (2010). "Comparison of the thermal reactivities of isolated lignin and holocellulose during pyrolysis," Fuel Process. Technol. 91(7), 759-764. DOI: 10.1016/j.fuproc.2010.02.009

Jiang, Z., Zhao, P., and Hu, C. (2018). "Controlling the cleavage of the inter- and intramolecular linkages in lignocellulosic biomass for further biorefining: A review," Bioresource Technol. 256, 466-477. DOI: 10.1016/j.biortech.2018.02.061

Jin, E., Zhang, Y., Hu, F., Yang, F., Wu, S., Jin, Y., and Song, J. (2017). “To understand the superior hydrolytic activity after polymorphic conversion from cellulose I to II from the adsorption behaviors of enzymes," Cellulose 24(3), 1371-1381. DOI: 10.1007/s10570-016-1183-8

Karimi, A., Nazari, S., Ghasemi, I., Tajvidi, M., and Ebrahimi, G. (2006). "Effect of the delignification of wood fibers on the mechanical properties of wood fiberpolypropylene composites," J. Appl. Polym. Sci. 102(5), 4759-4763. DOI: 10.1002/app.23967

Li, J., Hu, H., Li, H., Huang, L., Chen, L., and Ni, Y. (2017a). "Kinetics and mechanism of hemicelluloses removal from cellulosic fibers during the cold caustic extraction process," Bioresource Technol. 234, 61-66. DOI: 10.1016/j.biortech.2017.03.026

Li, X., Zhang, K., Shi, R., Ma, X., Tan, L., Ji, Q., and Xia, Y. (2017b). "Enhanced flameretardant properties of cellulose fibers by incorporation of acid-resistant magnesium- 
oxide microcapsules," Carbohyd. Polym. 176, 246-256. DOI:

10.1016/j.carbpol.2017.08.096

Liu, Y., Sun, B., Zheng, X., Yu, L., and Li, J. (2018). "Integrated microwave and alkaline treatment for the separation between hemicelluloses and cellulose from cellulosic fibers," Bioresource Technol. 247, 859-863. DOI: 10.1016/j.biortech.2017.08.059

Naduparambath, S., Jinitha, T. V., Shaniba, V., Sreejith, M. P., Balan, A. K., and Purushothaman, E. (2017). "Isolation and characterisation of cellulose nanocrystals from sago seed shells," Carbohyd. Polym. 180, 13-20. DOI: 10.1016/j.carbpol.2017.09.088

Nam, S., French, A. D., Condon, B. D., and Concha, M. (2016). "Segal crystallinity index revisited by the simulation of X-ray diffraction patterns of cotton cellulose I $\beta$ and cellulose II," Carbohyd. Polym. 135, 1-9. DOI: 10.1016/j.carbpol.2015.08.035

Nilsson, H., Galland, S., Larsson, P. T., Gamstedt, E. K., and Iversen, T. (2012). "Compression molded wood pulp biocomposites: A study of hemicellulose influence on cellulose supramolecular structure and material properties," Cellulose 19(3), 751760. DOI: $10.1007 / \mathrm{s} 10570-012-9688-2$

Ou, Y., and Huang, Q. (2003). "Study on the photo degradation of pulp mold container," J. Appl. Polym. Sci. 87(13), 2052-2056. DOI: 10.1002/app.11392

Park, S., Venditti, R. A., Jameel, H., and Pawlak, J. J. (2007). "Studies of the heat of vaporization of water associated with cellulose fibers characterized by thermal analysis," Cellulose 14(3), 195-204. DOI: 10.1007/s10570-007-9108-1

Ren, J.-L., Peng, F., Sun, R.-C., and Kennedy, J. F. (2009). "Influence of hemicellulosic derivatives on the sulfate kraft pulp strength," Carbohyd. Polym. 75(2), 338-342. DOI: 10.1016/j.carbpol.2008.08.011

Riansa-Ngawong, W., and Prasertsan, P. (2011). "Optimization of furfural production from hemicellulose extracted from delignified palm pressed fiber using a two-stage process," Carbohyd. Res. 346(1),103-110. DOI: 10.1016/j.carres.2010.10.009

Segal, L., Creely, J. J., Martin, Jr., A. E., and Conrad, C. M. (1959). “An empirical method for estimating the degree of crystallinity of native cellulose using the X-ray diffractometer," Text. Res. J. 29(10), 786-794. DOI: 10.1177/004051755902901003

Segmehl, J. S., Laromaine, A., Keplinger, T., May-Masnou, A., Burgert, I., and Roig, A. (2018). "Magnetic wood by in situ synthesis of iron oxide nanoparticles via a microwave-assisted route," J. Mater. Chem. C 6, 3395-3402. DOI: 10.1039/C7TC05849G

Shen, D. K., Gu, S., and Bridgwater, A. V. (2010). "The thermal performance of the polysaccharides extracted from hardwood: Cellulose and hemicellulose," Carbohyd. Polym. 82(1), 39-45. DOI: 10.1016/j.carbpol.2010.04.018

Spiegelberg, H. L. (1966). The Effect of Hemicelluloses on the Mechanical Properties of Individual Pulp Fibers, Ph.D. Dissertation, The Institute for Paper Chemistry, Lawrence University, Appleton, Wisconsin.

Tian, Y., Li, Y., Xu, X., and Jin, Z. (2011). "Starch retrogradation studied by thermogravimetric analysis (TGA)," Carbohyd. Polym. 84(3), 1165-1168. DOI: 10.1016/j.carbpol.2011.01.006

Wan, J., Wang, Y., and Xiao, Q. (2010). "Effects of hemicellulose removal on cellulose fiber structure and recycling characteristics of eucalyptus pulp," Bioresource Technol.101(12), 4577-4583. DOI: 10.1016/j.biortech.2010.01.026

Wang, Q., Xiao, S., Shi, S. Q., and Cai, L. (2018). "The effect of delignification on the properties of cellulosic fiber material," Holzforschung 72, 443-449. DOI: 10.1515/hf- 
2017-0183

Wang, Q., Xiao, S., Shi, S. Q., and Cai, L. (2017a). "Mechanical strength, thermal stability, and hydrophobicity of fiber materials after removal of residual lignin," BioResources 13(1), 71-85. DOI: 10.15376/biores.13.1.71-85

Wang, Q.-L., Yue, J.-Q., Xiao, S.-L., and Lu, X.-Z. (2017b). "Effects of initial moisture contents on properties of overloaded molded fiber materials under hot pressing conditions," J. Chem. Eng. Chin. Univ. 31(4), 951-959. DOI: 10.3969/j.issn.10039015.2017.04.028

Wang, Z.-W., and Li, X.-F. (2014). "Effect of strain rate on cushioning properties of molded pulp products," Mater. Design 57, 598-607. DOI: 10.1016/j.matdes.2014.01.019

Wu, Y., Xia, C., Cai, L., Garcia, A. C., and Shi, S. Q. (2018). "Development of natural fiber-reinforced composite with comparable mechanical properties and reduced energy consumption and environmental impacts for replacing automotive glass-fiber sheet molding compound," J. Clean. Prod. 184, 92-100. DOI: 10.1016/j.jclepro.2018.02.257

Xia, C., Wang, K., Dong, Y., Zhang, S., Shi, S. Q., Cai, L., Ren, H., Zhang, H., and Li, J. (2016a). "Dual-functional natural-fiber reinforced composites by incorporating magnetite," Compos. Part B-Eng. 93, 221-228. DOI:

10.1016/j.compositesb.2016.03.016

Xia, C., Zhang, S., Ren, H., Shi, S. Q., Zhang, H., Cai, L., and Li, J. (2016b). "Scalable fabrication of natural-fiber reinforced composites with electromagnetic interference shielding properties by incorporating powdered activated carbon,"Materials 9(1), 10. DOI: $10.3390 / \mathrm{ma9} 010010$

Xie, J., Hse, C.-Y., Hoop, C. F. D., Hu, T., Qi, J., and Shupe, T. F. (2016). "Isolation and characterization of cellulose nanofibers from bamboo using microwave liquefaction combined with chemical treatment and ultrasonication," Carbohyd. Polym. 151, 725734. DOI: 10.1016/j.carbpol.2016.06.011

Zhang, Y., Yu, G., Li, B., Mu, X., Peng, H., and Wang, H. (2016). "Hemicellulose isolation, characterization, and the production of xylo-oligosaccharides from the wastewater of a viscose fiber mill," Carbohyd. Polym. 141, 238-243. DOI: 10.1016/j.carbpol.2016.01.022

Zhao, X., and Liu, D. (2012). "Fractionating pretreatment of sugarcane bagasse by aqueous formic acid with direct recycle of spent liquor to increase cellulose digestibility-The formiline process," Bioresource Technol. 117, 25-32. DOI: 10.1016/j.biortech.2012.04.062

Article submitted: February 25, 2019; Peer review completed: May 3, 2019; Revised version received: May 10, 2019; Accepted: May 15, 2019; Published: May 21, 2019. DOI: $10.15376 /$ biores.14.3.5288-5300 